\title{
Factors accounting for asthma variability: achieving optimal symptom control for individual patients
}

\author{
*Barbara P Yaw n ${ }^{a, b}$ \\ a Olmsted M edical Center, Rochester, Minnesota, USA \\ ${ }^{\mathrm{b}}$ Adjunct Professor, University of Minnesota, Department of Family and Community Health
}

Received 20th October 2006; revised version received 22nd August 2007; accepted 26th October 2007; online 12 th M arch 2008

\begin{abstract}
Asthma is a variable disease, and various factors can lead to an increase (or decrease) in asthma symptoms and the level of asthma control. Pub M ed was searched for recent articles dealing with asthma variability, environmental factors and co-morbid conditions that affect asthma control, and for publications which identified tools to facilitate patients' response to asthma variability. Variability in asthma symptoms may be a response to the individual's environment (e.g. seasonal variation, cigarette smoke, and air pollutants) or personal factors (e.g. inhaler technique, pregnancy, exercise). Co-morbid diseases such as allergic rhinitis may also impact significantly on asthma

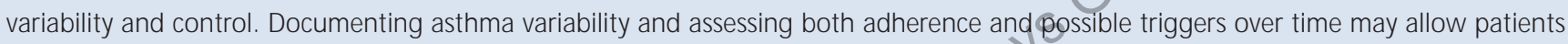
and physicians to develop treatment programmes that anticipate, rather than follow, changes in the level of asthma symptoms. Personalised asthma control plans which take into account factors affecting symptom variability may enable patients to modify medication and their environment prophylactically in anticipation of a known trigger orat the first sign of an asthma exacerbation.
\end{abstract}

(C) 2008 General Practice Airways Group. All rights reserved.

BP Yawn. Prim Care Resp J 2008; 17(3): 138-147.

doi:10.3132/pcrj.2008.00004

Keyw ords asthma, variability, control, symptoms, environment, treatment, treatment plans

\section{Contents}

Background

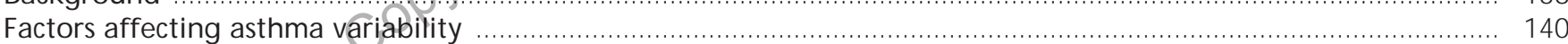

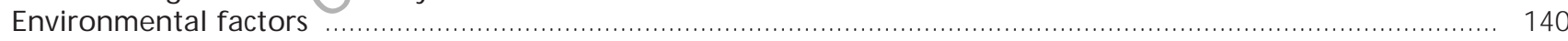

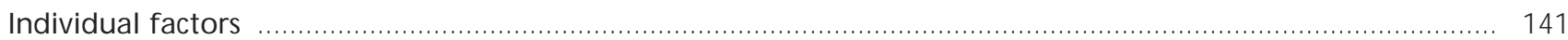

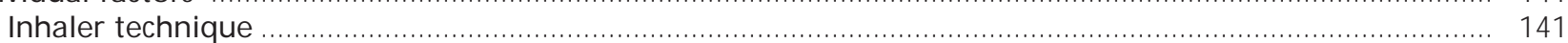

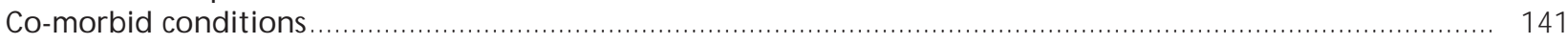

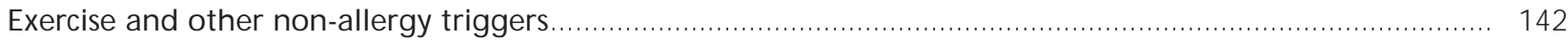

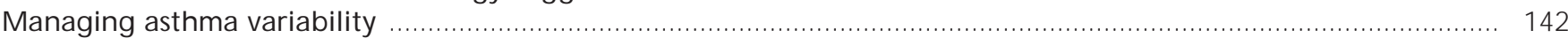

Ensuring adequate knowledge of medication and delivery devices .................................................................... 142

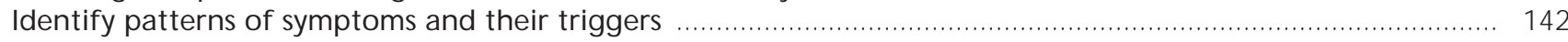

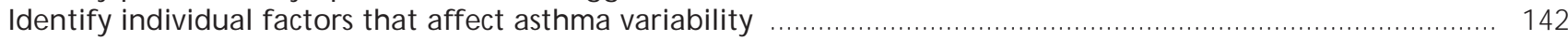

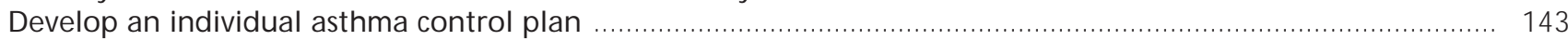

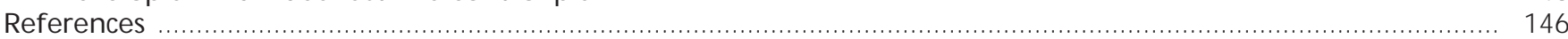

\section{See Appendix A at www.thepcri.org}

\section{Background}

Asthma imposes a significant clinical, social, and economic burden. In 2003, approximately $3 \%$ of adults and $6 \%$ of children in the US had an asthma attack. ${ }^{1}$ Although the overall rate of asthma mortality is decreasing in the US, ${ }^{2}$ the risk of death in patients even with mild asthma is a continued problem.

Asthma diagnostic and management guidelines recommend a stepwise approach to treatment, indicating that the lowest effective doses of medication should always

\footnotetext{
* Corresponding author: Department of Research, Olmsted Medical Center, Rochester, M innesota 55904, USA.
}

Tel: +1 (507) 2872758 Fax: +1 (507) 2872722 E-mail: yawnx002@umn.edu. 
Copyright GPIAG - reproduction prohibited

Table 1. Classification of asthma severity by clinical features before treatment and recommended treatment options $5^{3,4}$

\begin{tabular}{|c|c|c|}
\hline Classification & Symptoms and lung function & $\begin{array}{l}\text { Recommended treatment options } \\
\text { All levels: inhaled rapid-acting } \beta 2 \text {-agonist for symptom relief* } \\
\text { (not more than 3-4 times daily) }\end{array}$ \\
\hline Intermittent $^{\dagger}$ & $\begin{array}{l}\text { Symptoms less than once a week } \\
\text { Brief exacerbations } \\
\text { Nocturnal symptoms } \leq 2 \times / \text { month } \\
\text { FEV }_{1} \text { or PEF } \geq 80 \% \text { predicted } \\
\text { PEF or FEV } 1 \text { variability }<20 \%\end{array}$ & $\begin{array}{l}\text { Controller: } \\
\text { None necessary }\end{array}$ \\
\hline Mild persistent & $\begin{array}{l}\text { Symptoms }>\text { once/week but }<\text { once/day } \\
\text { Exacerbations may affect activity and sleep } \\
\text { Nocturnal symptoms }>2 x / \text { month } \\
\mathrm{FEV}_{1} \text { or } \mathrm{PEF} \geq 80 \% \text { predicted } \\
\text { PEF or } \mathrm{FEV}_{1} \text { variability } 20-30 \%\end{array}$ & $\begin{array}{l}\text { Preferred controller: } \\
\text { Low-dose inhaled corticosteroid } \\
\text { Alternatives: } \\
\text { Sustained-release theophylline or } \\
\text { Cromone or } \\
\text { Leukotriene modifier }\end{array}$ \\
\hline Moderate persistent & $\begin{array}{l}\text { Symptoms daily } \\
\text { Exacerbations may affect activity and sleep } \\
\text { Nocturnal symptoms }>1 \text { /week } \\
\text { Daily use of inhaled short-acting } \beta 2 \text {-agonist } \\
\mathrm{FEV}_{1} \text { or PEF } 60-80 \% \text { predicted } \\
\text { PEF or FEV } 1 \text { variability }>30 \%\end{array}$ & $\begin{array}{l}\text { Preferred controller: } \\
\text { Low-to-medium dose inhaled corticosteroid plus long-acting } \beta 2 \text {-agonist } \\
\text { Alternatives: } \\
\text { Medium-dose inhaled corticosteroid plus sustained release theophylline, or } \\
\text { Medium-dose inhaled corticosteroid plus long-acting oral } \beta 2 \text {-agonist, or } \\
\text { High-dose inhaled corticosteroid, or } \\
\text { Medium-dose inhaled corticosteroid plus leukotriene modifier }\end{array}$ \\
\hline Severe persistent & 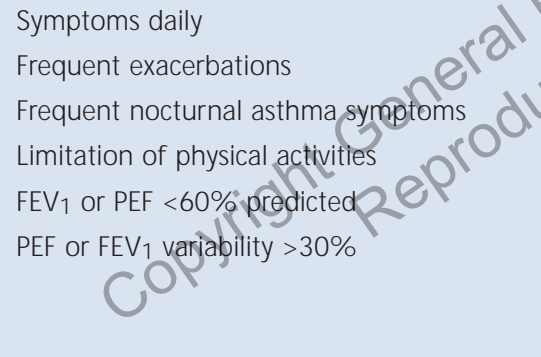 & $\begin{array}{l}\text { High-dose inhaled corticosteroid plus long-acting inhaled } \beta 2 \text {-agonist, plus } \\
\text { one or more of the following, if needed: } \\
\text { Sustained-release theophylline } \\
\text { Leukotriene modifier } \\
\text { Long-acting oral } \beta 2 \text {-agonist } \\
\text { Oral corticosteroid } \\
\text { Anti-lgE }\end{array}$ \\
\hline
\end{tabular}

$\mathrm{FEV}_{1}=$ forced expiratory volume in 1 second; $\mathrm{PEF}=$ peak expiratory flow; $\lg \mathrm{E}=$ immunoglobulin $\mathrm{E}$.

*Other options for reliever medications are (in increasing order of cost): inhaled anticholinergic, short-acting oral $\beta 2$-agonist, and short-acting theophylline.

${ }^{\dagger}$ Patients with intermittent asthma but severe exacerbations should be treated as having moderate-persistent asthma.

${ }^{\ddagger}$ Current evidence supports use in patients $\geq 12$ years only.

be used. This approach is currently based on four asthma severity categories: intermittent, mild persistent, moderate persistent, and severe persistent ${ }^{3,4}$ (see Table 1). The recommended first-line treatment for persistent asthma is an inhaled corticosteroid (ICS), with the addition of a long-acting $\beta 2$-agonist (LABA) for continuous symptoms which are not responsive to ICS treatment alone. Full details of all recommended medications are provided in Table 1.

The goals of asthma therapy, as defined by the National Asthma Education and Prevention Program (NAEPP), are outlined in Table 2. Despite the availability of effective medications and treatment strategies, many patients continue to report hospitalisations, missed school or work days, and suboptimal pharmacotherapy. ${ }^{5}$ One reason for this may be fluctuations in patients' asthma symptoms - i.e. fluctuating levels of asthma "control". This was illustrated by Calhoun and colleagues, ${ }^{6}$ who demonstrated that out of 85 patients with moderate or severe persistent asthma at baseline, approximately $70 \%$ experienced one or more changes in morning peak expiratory flow (PEF) that were 
Table 2. National asthma education and prevention programme goals of asthma therapy ${ }^{4}$

- Prevent chronic symptoms (e.g. no sleep disruption or missed days from school or work)

- Maintain (near) "normal" pulmonary function

- Maintain "normal" activity levels (including exercise and other physical activity)

- Prevent recurrent exacerbations of asthma and minimise the need for emergency department visits or hospitalisations

- Provide optimal pharmacotherapy with minimal or no adverse effects

- Meet patient and family expectations of - and satiffaction with - asthma care

consistent with a change in severity level. Moreover, nearly half experienced five or more such changes during the 12week study periods (see Figure 1 ). ${ }^{6}$

In addition to day-to-day and day-to-night changes in asthma symptoms, various factors are known to aggravate the disease. Exposure to these intrinsic and extrinsic factors makes it appear as though patients are shifting from one level of severity classification to another over time (e.g. mild persistent to moderate persistent), and this can trigger periodic exacerbations or "attacks" .

Treatment regimens often do not take such variations into account and may lead to over- or undertreatment during periods of good or poor control, respectively. The 2007 NAEPP guidelines ${ }^{4}$ define control based on impairment and

Figure 1. Percentage of patients experiencing changes in asthma severity on the basis of per cent predicted morning peak expiratory flow (analysis from two 12week studies). ${ }^{6}$

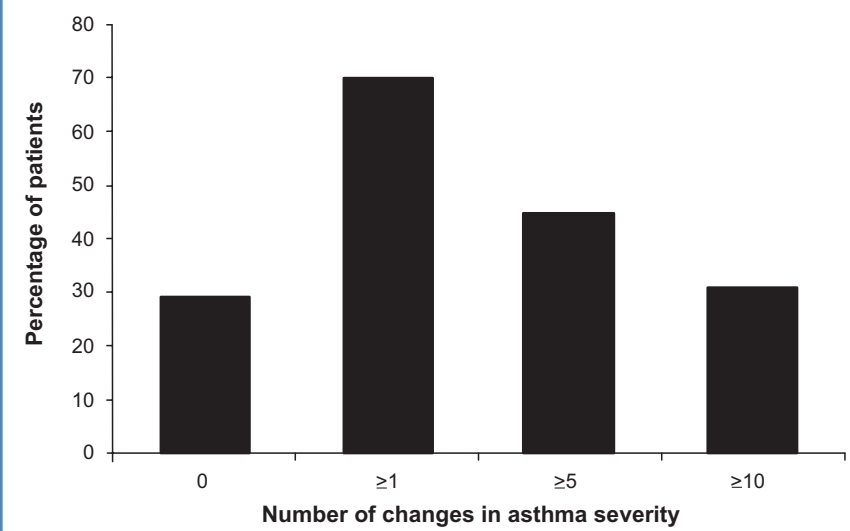

risk; symptom frequency, missed activity days, and occurrence of exacerbations requiring medical attention. ${ }^{7,8}$ Current guidelines recommend that physicians react to changes in the frequency and intensity of symptoms by adjusting therapy over time to improve asthma symptoms and minimise the occurrence of exacerbations. ${ }^{4}$ However, in practice, it is preferable to be proactive, aiming to increase medication in order to maintain asthma control upon exposure to precipitating factors such as the onset of the allergy season or exposure to smoke or air pollution. M odifying asthma control plans to include a patient's known or suspected causes of exacerbations (e.g. seasonal allergies) would provide the patient with the means to initiate rapid and pre-agreed changes in medication at the first signs of asthma worsening, and prophylactically to increase controller medications upon anticipated exposure to their individual triggers. ${ }^{9.12}$ It is therefore important to understand which factors can affect asthma variability in order to ensure that patients receive optimal treatment at all times.

\section{Factors affecting asthma variability Environmental factors}

In the US, the incidence of hospitalisations or emergency department visits for asthma varies seasonally, peaking in the autumn and reaching a low point during the summer (see Figure 2). ${ }^{13}$ This seasonal pattern also varies with age: children and young adults show an autumnal peak in asthma morbidity and a summer peak in mortality, ${ }^{13,14}$ whereas those aged 65 years or older have greater asthma morbidity and mortality in the winter. ${ }^{14}$ Possible determinants of seasonal

Figure 2. Seasonal fluctuations in the weekly average number of emergency department visits by asthma patients over a 10-year period (1991-2000) in 11 New York City municipal hospitals. ${ }^{13}$

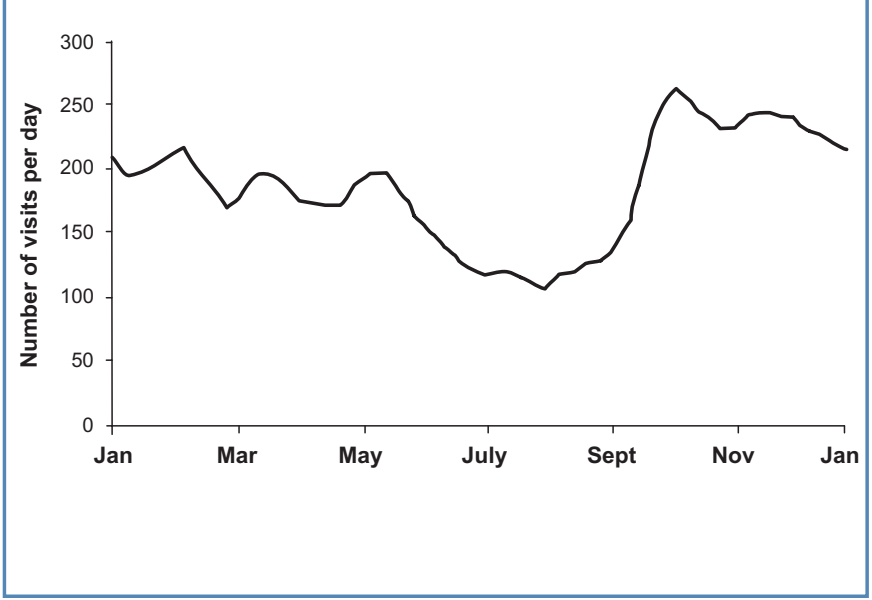


fluctuations include increased exposure to allergens such as pollens, house-dust mites, ${ }^{15}$ and mould spores $^{16}$ in the younger population, and influenza or other respiratory tract infections in the older population. Recognising each patient's unique seasonal patterns has practical implications for patient care, including the need to consider a pre-allergy season office visit, closer monitoring at home, and increased medication for patients entering a season of higher risk. ${ }^{17,18}$

Cigarette smoke, including second-hand smoke, is one of the most common asthma triggers ${ }^{19,20}$ and can lead to increased bronchodilator use in children. ${ }^{21}$ Indoor air pollutants (e.g. cockroaches, mould, and house-dust mites) can worsen a patient's asthma, ${ }^{4}$ and outdoor air pollutants including ozone and particulate matter - affect asthma symptoms in children..$^{22,23}$ Inhalation of toxic vapours from industrial fumes, bleach, sulphur, or smoke from fire or tobacco was closely associated with rapid onset of fatal or near-fatal acute exacerbations (defined as a respiratory crisis developing in two hours or less). ${ }^{24}$

Viral upper respiratory tract infections (URTIS), in particular infection with human rhinovirus, are linked to a substantial proportion of asthma exacerbations. A study of emergency hospitalisations for asthma among 106 children with asthma, admitted 136 times over a 12-month period, found that URTIs were the trigger in $63 \%$ of episodes..$^{25}$ Knowing that an URTI often triggers bronchospasm in an individual makes it possible to increase medications at the onset of URT symptoms.

\section{Individual factors}

\section{Inhaler technique}

The large number of inhalers currently available has made choosing and using the most appropriate delivery device confusing for both patients and physicians. Poor inhaler technique for both metered-dose and dry powder inhalers is often observed in asthma patients and is associated with an increased risk of death. ${ }^{26}$ Although appropriate training can enable patients to use inhalers effectively, regular reinforcement of good inhaler technique is recommended to maintain this standard..$^{3,4}$

\section{Co-morbid conditions}

Personal characteristics can also lead to changes in lung function. There is a strong relationship between allergic rhinitis (AR) and asthma - 75-80\% of patients with asthma are believed to have $A R^{27}$ The nose and the bronchi are parts of a common airway with similar allergic inflammatory mechanisms, mediators, and lining cells, suggesting that asthma and AR may reflect manifestation of the same inflammatory process in different end organs (the lung and the nose). ${ }^{27}$ While the conditions may reflect a parallel process affected by the same triggers, there is some evidence that AR and asthma severity do not occur in paralle ${ }^{28}$ and that controlling AR may improve the control of asthma. ${ }^{27}$

In healthy individuals, lung function exhibits a circadian rhythm, reaching a maximum in the afternoon and a minimum in the early morning. ${ }^{29}$ In nocturnal asthma, there is an exaggeration of this normal variation, which is associated with changes in lung function of more than $15 \%$ and which can be aggravated by gastro-oesophageal reflux disease (GORD) or obesity. ${ }^{29}$

Asthma often coexists with GORD, but the association is not always clear. Some patients can link increase in asthma symptoms to periods of reflux. Others report no apparent association. Review of the existing literature fails to clarify the direction of causality if indeed causality rather than just association is present..$^{30}$ How ever, in patients with difficult-tocontrol asthma or nocturnal asthma, a few simple questions (see Appendix A, available online at www.thepcrj.org) can identify the need for further evaluation or a therapeutic trial of GORD medication. ${ }^{31}$ Even with symptoms suggesting a link, it is difficult to predict which patients will show improvements in their asthma after treatment for GORD. ${ }^{30}$

Obesity is wellikknown as a risk factor for hypertension, diabetes, and atherosclerosis, and increasing evidence indicates that it Omay also be a risk factor for asthma. ${ }^{32}$ Potential mechanisms affecting asthma in obesity include Cisease-related changes in lung volume, systemic inflammation, and other adipocyte-derived factors that might opromote airway narrowing. ${ }^{32}$ Such factors associated with obesity can lead to variability in peak expiratory flow (PEF); these PEF variations can decrease after weight loss. ${ }^{33}$

Women may experience premenstrual or peri-menstrual worsening of asthma symptoms. ${ }^{34,35}$ The frequency of increased symptoms and decline in lung function (PEF) has been estimated to be as high as $30-40 \%$ in women attending specialty clinics or visiting emergency departments. ${ }^{36,37}$ Diagnosis requires careful recording of daily symptoms and PEF levels. The aetiology remains unknown but has been hypothesised to be related to normal fluctuations in hormone levels that may be associated with changes in beta-adrenergic receptor responsiveness, airway hyper-reactivity and increased airway oedema. ${ }^{35}$ However, the association may be more complex since women with asthma are at increased risk of irregular menses and therefore perhaps greater variations in sex hormones..$^{38}$ Some association with sex hormones is also suggested by the course of asthma during pregnancy - when about one third of women's asthma improves, one third remains the same, and one third declines, without a direct relationship to pre-pregnancy levels of control or severity.37

Patients with asthma are more likely to report co-morbid diabetes than the general population. ${ }^{39}$ When these two conditions coexist, treatment of one can often exacerbate the other. Although ICS have been shown to have no effect on 
the risk of developing diabetes, oral corticosteroids can increase susceptibility to, and the control of, diabetes. ${ }^{40}$ Consequently, it is important to obtain good asthma control (by inhaled treatment) in patients with diabetes, thereby preventing asthma exacerbations which might necessitate treatment with oral corticosteroids.

Exercise and other non-allergy triggers

Asthma symptoms can also be triggered by exercise. Exerciseinduced bronchoconstriction is estimated to occur in 50-60\% of patients with asthma. ${ }^{41}$ In addition, some patients experience increased asthma symptoms in response to ingestion of aspirin, nonsteroidal anti-inflammatory drugs, or beta blockers. ${ }^{42,43}$ Psychosocial variables, such as mood and stress, have also been noted to influence asthma symptoms in some patients. ${ }^{44}$

\section{Managing asthma variability}

In patients treated with appropriate levels of medication (i.e. low-to-moderate doses of ICS alone or a combination of ICS and LABA), total or well-controlled asthma is achievable in most patients, ${ }^{45}$ and this is a key objective of asthma therapy. ${ }^{3,4}$ However, through development of the US federallyfunded Asthma APGAR (Activities, Persistence, triGGers, Asthma medications, and Response to therapy) model ${ }^{46}$ it is apparent that a step down in asthma therapy seldom occurs when primary care physicians see patients for return visits. Furthermore, patients may initiate their own step-down or may discontinue therapy inappropriately; such non-adherence may contribute to the high rates of asthma-related emergency department visits. ${ }^{47}$

In patients who adhere to prescribed doses, treatment regimens that are not periodically re-evaluated may not adequately address asthma variability. Moreover, when asthma is managed strictly according to "severity", short-term variability in asthma symptoms and lung function may not be taken into account, and changes in prescribed medication may lag behind changes in symptom frequency and intensity. Therefore, short-term fluctuations in asthma should be taken into account when developing asthma control plans. Personalised control plans allow patients to manage their asthma within pre-defined agreed limits and, when tailored to patients' triggers and symptom patterns, should aim to guide patients so that they respond appropriately and promptly to signs of asthma worsening and can increase their medication prophylactically in anticipation of trigger exposure. ${ }^{9-11,17,18}$

\section{Ensuring adequate know ledge of medication and delivery devices}

Personalised action plans that ask patients to participate in self-management are based on the patient's knowledge of the purpose, time of onset, and duration of action of their medications. ${ }^{9 \cdot 11,17,18,48}$ It is not uncommon for patients in the emergency department to be confused about which inhaler is the "rescue" inhaler (short-acting $\beta 2$-agonist) and which is the "controller" (ICS or combination ICS and LABA). The use of coloured stickers - red for rescue and green or yellow for controller medications - can help patients to remember. However, knowing which medication is which does not help if the patient does not know how to use their inhaler properly.

Early in the series of asthma visits, patients should be made aware of the type of medications they receive and how and when they should be used. This should be reinforced during regular physician visits by asking the patient to bring all medications and inhalers to each visit and to describe the purpose of each medication or inhaler they brought with them. Patients should understand that reliever medications (e.g. rapid-acting $\beta 2$-agonists) should be used for acute attacks or sudden increases or onset of symptoms and that their controller medications (e.g. ICS, LABAs, leukotriene modifiers) are essential to control underlying disease, even though the effects of the controller may not be felt immediately.

\section{Identify patterns of symptoms and their triggers}

Developing a personalised asthma control plan that takes into account variations in a patient's asthma requires the patient to recognise triggers and seasonal patterns. ${ }^{9 \cdot 11,17,18}$ While daily symptom and trigger diaries are often impractical, notes on a calendar kept on the refrigerator can be helpful since possible triggers or times of worsening can be listed directly on the date of occurrence. These should be reviewed at regular physician visits. It is easier to identify potential asthma triggers if information is collected regularly rather than by trying to reconstruct patterns w eeks or months later. Many patients fail to identify variations in the level of asthma symptoms as being important and do not report them during visits unless questioned specifically. A checklist, such as that shown in Table 3, can be provided to aid record-keeping. It is important to obtain a full profile of the factors affecting a patient's dayto-day asthma control, including allergen exposure and seasonal variations with increased symptoms, ${ }^{8}$ to allow intensive management at such times, and thereby maximise the efficacy of his/her asthma management.

\section{Identify individual factors that affect asthma variability}

Co-morbid conditions such as obesity, GORD, and AR are often ignored by the patient or managed with over-thecounter drugs. If physicians do not ask about symptoms such as recurrent heartburn or nasal congestion or rhinorrhea, they may never learn of these co-morbid conditions since patients or caregivers may not link the non-lung symptoms with asthma control. Conditions to explore are listed in Table 3. Effective treatment of $A R^{49}$ can significantly reduce emergency department visits and asthma-related hospitalisations. ${ }^{50}$ 
Table 3. Checklist for factors to consider when assessing reasons for poor control

\begin{tabular}{|c|c|}
\hline Checklist for factors i & fluencing the patient's asthma control \\
\hline Technique & Does not understand the role of each medication in disease control (rapid relief versus preventive) \\
\hline & Is not using the drug devices properly (pMDI, DPI, nebuliser) \\
\hline & Cannot determine peak flow, if applicable (cannot use or does not own a peak flow meter) \\
\hline Environmental triggers & Cigarette smoke (passive) \\
\hline & Pets (animal dander) \\
\hline & Viral respiratory tract infection (e.g. human rhinovirus) \\
\hline & Seasonal allergens (e.g. pollen) \\
\hline & House-dust mites \\
\hline & Mould spores \\
\hline & Indoor pollutants (e.g. particulate matter, nitrogen dioxide) \\
\hline & Outdoor pollutants (e.g. ozone, particulate matter, industrial fumes) \\
\hline Individual factors & Allergic rhinitis \\
\hline & Circadian rhythm \\
\hline & Gastro-oesophageal reflux disease (nocturnal and recumbent symptoms with (mechanical and "acid" irritation) \\
\hline & Obesity 15 \\
\hline & Menstrual cycle (worsening of asthma during premenstrual phase)d \\
\hline & Pregnancy \\
\hline & Exercise \\
\hline & Drugs (e.g. aspirin and other nonsteroidal anti-inflammatory drugs, beta-blockers) \\
\hline & Psychosocial variables (e.g. mood and stress) \\
\hline
\end{tabular}

Treating GORD in both adults and children with concomitant asthma can result in improved lung function and/or a significant reduction in the need for asthma medications. However, not all patients improve with even very aggressive GORD therapy and it is difficult to predict which patients will benefit. ${ }^{30}$ In some patients controlling asthma may actually improve GORD rather than vice versa. ${ }^{30}$ Weight loss has been shown to improve lung function in obese women ${ }^{51}$ but data is not available for children or men.

During pregnancy, lack of asthma control can result in preterm birth, intrauterine growth restriction, perinatal mortality, and small-for-gestational-age infants. ${ }^{52}$ It is important to treat asthma with the safest and best available therapy to reduce foetal exposure to the potential hypoxia and stress of uncontrolled maternal asthma. Both ICS or $\beta 2$ agonist therapy can be used, as they do not increase perinatal risks and effectively control asthma for most women. ${ }^{53,54}$

In patients who experience exercise-induced bronchoconstriction (EIB), prophylactic symptom control, usually with short-acting $\beta 2$-agonists, can reduce the risk of an exacerbation. ${ }^{41}$ People with daily EIB should be considered for long-term controller therapy rather than daily or multiple daily doses of a rescue medication use prophylactically.

\section{Develop an individualised asthma control plan}

An example of an asthma control plan is outlined in Figure 3 , and this can be tailored to the individual patient. In addition to the items found in many asthma control plans, space is provided to note individualised factors affecting the patient's asthma and what action should be taken if these are, or are about to be, encountered (Table 4). For example, if the patient has AR that aggravates his/her asthma, the asthma control plan should specify AR under "Things that make your asthma worse" and should indicate the physician-recommended treatment (under "Treat other diseases that make your asthma worse").

By taking a more personalised approach that allows the patient to set goals and help determine appropriate actions, this plan aims to maximise asthma control using the lowest effective dose of medication. Development and implementation of the plan should be a joint effort between the patient and his/her physician and should be reviewed at regular intervals. By involving patients and ensuring that they 


\section{Figure 3. Example of a personalised asthma control plan}

\begin{tabular}{|c|c|c|}
\hline Asthma control plan & \multicolumn{2}{|l|}{ For: } \\
\hline Doctor's name: & Friend's name: & Date: \\
\hline Doctor's phone no.: & Friend's phone no.: & Initial/revised plan \\
\hline \multicolumn{3}{|l|}{ Things that make your asthma worse: } \\
\hline \multicolumn{3}{|l|}{ Triggers: } \\
\hline \multicolumn{3}{|l|}{ Diseases: } \\
\hline \multicolumn{3}{|l|}{ Medications: } \\
\hline GREEN ZONE - OK! & \multicolumn{2}{|c|}{$\begin{array}{c}\text { Use these medicine(s) daily and, when possible, avoid } \\
\text { triggers to keep asthma under control } \\
\text { Take actions indicated below for activities, diseases, } \\
\text { and unavoidable triggers }\end{array}$} \\
\hline This is how you should feel every day & Medicine & When \\
\hline \multicolumn{3}{|l|}{ Good breathing } \\
\hline \multicolumn{3}{|l|}{ No cough, wheezing, or shortness of breath } \\
\hline \multicolumn{3}{|l|}{ Normal sleep } \\
\hline \multicolumn{3}{|l|}{ Can work/play } \\
\hline \multicolumn{2}{|c|}{ AND (if a peak flow meter is used) peak flow is more than $80 \%$ of my best: } & $80 \%$ \\
\hline \multicolumn{3}{|l|}{ Before exercise or sports you should: } \\
\hline \multicolumn{3}{|c|}{ If you come into contact with any of your triggers you should: } \\
\hline \multicolumn{3}{|c|}{ Treat other diseases that make your asthma worse: } \\
\hline \multicolumn{3}{|l|}{ Disease: } \\
\hline \multicolumn{3}{|l|}{ YELLOW ZONE - Caution } \\
\hline Your asthma is getting worse & Medicine & When \\
\hline \multicolumn{3}{|l|}{ Cough or wheeze } \\
\hline \multicolumn{3}{|l|}{ Tight chest } \\
\hline \multicolumn{3}{|c|}{ Wake up at night due to asthma } \\
\hline \multicolumn{3}{|c|}{ Can do some, but not all, usual activities } \\
\hline \multicolumn{3}{|l|}{$\begin{array}{l}\text { Peak flow is between: } \\
\text { (50-80\% of my personal best) }\end{array}$} \\
\hline \multicolumn{3}{|c|}{ If you do not return to the green zone after 1 hour you should: } \\
\hline \multirow{2}{*}{$\begin{array}{l}\text { Call your doctor (tel: } \\
\text { Take: }\end{array}$} & & \\
\hline & & \\
\hline \multicolumn{3}{|l|}{ (relief medication) $\quad$ (steroid) } \\
\hline \multicolumn{3}{|c|}{ If you return to the green zone after one hour you should: } \\
\hline RED ZONE - Danger & Call your d & $\begin{array}{l}\text { eone to take you } \\
\text { diately }\end{array}$ \\
\hline Call your doctor right away & Medicine & When \\
\hline Medicine is NOT helping & & \\
\hline Breathing is difficult & & \\
\hline Lips or fingernails turn blue/grey & & \\
\hline Hard to walk and/or talk & & \\
\hline Ribs or neck muscles show when breathing & $\begin{array}{l}\text { Call your family } \mathbf{d} \\
\text { If you are unable to }\end{array}$ & lutes and \\
\hline Repeated wheeze at rest & $\begin{array}{l}\text { you are still in the re } \\
\text { Go to the hospital o }\end{array}$ & 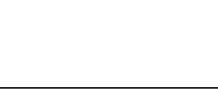 \\
\hline $\begin{array}{l}\text { OR peak flow is below: } \\
\text { (less than } 50 \% \text { of my best) }\end{array}$ & $\begin{array}{l}\text { If you have troubl } \\
\text { blue you should g } \\
\text { Take }\end{array}$ & /fingernails turn \\
\hline
\end{tabular}


Copyright GPIAG - reproduction prohibited

Table 4. Control measures for triggers',41

Trigger Control measures: instructions to patients

Allergens

House-dust mites

Animals

Cockroaches

Pollens

Mould

Tobacco smoke

Rhinitis

Sinusitis

Gastro-oesophageal reflux

Sulfite sensitivity

Medication

interactions

Occupational exposures

Viral respiratory

tract infections
Essential. Keep mattress and pillow in an airtight (allergen-impermeable) cover. Wash bed covers, clothes, and stuffed toys once a week in hot water $\left(\geq 130^{\circ} \mathrm{F}\right)$

Desirable. Reduce humidity to less than $50 \%$. Remove carpets from bedroom. Avoid sleeping or lying on upholstered furniture. If you must vacuum, use a dust mask

If possible, remove the animal from the home. If the pet must be indoors, keep it outside the patient's bedroom. Choose a pet without fur or feathers. Do not visit homes with pets, or take appropriate asthma medicine before going. Do not buy or use products made with feathers or kapok. Use a vacuum cleaner with a HEPA filter. Wash hands and clothes after contact with pets

Use insect sprays and cockroach traps. Do not leave garbage exposed

Stay indoors at midday and in the afternoon when pollen counts are highest. Keep windows closed in cars and at home. Use air conditioning if possible. Keep pets indoors or outdoors and do not allow them to go in and out of the home. If you must mow the lawn, use a pollen filter mask

Avoid sources of moulds (wet leaves, garden debris, dried wood). Avoid standing water or areas of poor drainage. Consider reducing humidity to less than $50 \%$

Stop smoking. Reduce exposure to other sources of tobacco smoke, such as smoke from day-care providers, visitors to the home, and co-workers

Use intranasal corticosteroids and antihistamines as prescribed

Use medical measures to promote drainage and decrease congestion

i. C :

Do not eat within 3 hours of bedtime. Avoid alcohol or chocolate in the evening. Elevate the head of bed by six to eight inches. Take appropriate medication as directed

Avoid eating shrimp, dried fruit, or processed potatoes. Do not drink beer or wine

Do not use beta-blockers (including ophthalmologic preparations)

Aspirin and other nonsteroidal anti-inflammatory drugs can cause severe and even fatal episodes for patients with severe persistent asthma, nasal polyps, or a history of aspirin sensitivity. Safe alternatives usually include acetaminophen and salsalate

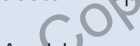

Avoidance, good ventilation, respiratory protection, and a tobacco smoke-free environment are the most effective measures

Patients with persistent asthma should receive annual influenza vaccinations. Wash hands often when around those with respiratory tract infections understand the rationale behind changes in dose or medication, they are more likely to adhere to treatment regimens - for example, the most frequently cited reasons for non-adherence to ICS treatment are patients' beliefs that ICS are unnecessary during asymptomatic periods and their concerns about adverse effects. ${ }^{55}$ Addressing these beliefs while developing an action plan could enhance patient understanding and might help modify fears.

The importance of having good patient-physician interaction in modern asthma management should not be overlooked. Improved physician communication is strongly correlated with greater satisfaction with the care received. ${ }^{56}$ Furthermore, direct clinician-to-patient feedback has been shown to improve adherence, ${ }^{57}$ and regular medical review can have a significant impact on patient outcomes in asthma. ${ }^{58}$ The individualised management plan can be used as the basis for regular asthma follow-up visits. Each visit should include a review of current medications, inhaler technique, any new triggers noted, and whether the use of the management plan has controlled symptoms. Regular review of management plans helps patients to understand their important role in asthma management and control. ${ }^{10}$

A systematic review on the use of personalised asthma action plans has been published recently. ${ }^{59}$ Few studies have been published that have used control-based action plans or control scores as a routine part of primary care asthma 
management. Such studies are in progress and soon data should be available to confirm whether or not the suggestions outlined in this review (drawn from the management of other chronic diseases) can be used with validated asthma control scores in order to improve asthma care and patient outcomes. ${ }^{60-69}$

\section{Acknow ledgement}

I thank Dawn Littlefield for secretarial support in preparing this work.

\section{Funding declaration}

M edical writing support was funded by AstraZeneca. However, responsibility for the opinions, conclusions and interpretation of the data lies solely with the author, who did not receive pharmaceutical company funding for this work.

\section{Conflict of interest declaration}

The author is a member of the National Institutes of Health's National Asthma Education and Prevention Program and the National Heart, Lung, and Blood Institute's Expert Review Panel 3 for updating asthma guidelines. She serves on the National Patient and Professional Asthma Advisory Committee for AstraZeneca and the Schering-Plough National Respiratory Disease Leadership Council, and has served as a consultant to Altana Pharma for asthma-related topics. She also has research grants in asthma-related topics from the National Heart, Lung, and Blood Institute, and the Agency for HealthCare Research and Quality and Schering-Plough Integrated Therapeutics.

\section{References}

1. National Center for Health Statistics. Health, United States, 2005 With Chartbook on Trends in the Health of Americans. Hyattsville, Maryland: 2005.

2. Sly RM. Continuing decreases in asthma mortality in the United States. Ann Allergy Asthma Immunol 2004;92:313-18.

3. Global Initiative for Asthma (GINA). Global strategy for asthma management and prevention. Updated 2005. Available at URL http://www.ginasthma.org accessed 10.01.2006.

4. EPR-Update 2007. Expert Panel Report 3 (EPR 3): Guidelines for the diagnosis and management of asthma. NIH Prepublications copy No . 08-4051. Bethesda, MD: US Department of Health and Human Services: National Institutes of Health; National Heart, Lung, and Blood Institute: National Asthma Education and Prevention Program, August 2007. Available at http://www.nhlbi. nih.gov/guidelines/asthma/asthgdln.htm.

5. Adams RJ, Fuhlbrigge A, Guilbert T, Lozano P, Martinez F. Inadequate use of asthma medication in the United States: results of the asthma in America national population survey. J Allergy Clin Immunol 2002;110:58-64.

6. Calhoun WJ, Sutton LB, Emmett A, Dorinsky PM. Asthma variability in patients previously treated with $\beta, 2$-agonists alone. J Allergy Clin Immunol 2003; 112:1088-94.

7. Vollmer WM. Assessment of asthma control and severity. Ann Allergy Asthma Immunol 2004;93:409-13.

8. Yawn BP, Yawn RA. Measuring asthma quality in primary care: can we develop better measures? Respir Med 2006;100:26-33.

9. Levy ML Robb M Allen J Doherty C Bland JM Winter RJ. A randomised controlled evaluation of specialist nurse education following accident and emergency department attendance for acute asthma. Respir Med 2000; 94(9):900-08.

10. Reddel HK. The benefit of experience: patient perception of asthma selfmanagement. Prim Care Resp J 2007;16(2):68-70. doi:10.3132/pcri.2007. 00022

11. MCDonald VM, Gibson PG. Asthma self-management education. Chron Respir Dis 2006;3(1):29-37.

12. Charlton I. Evaluation of peak flow and symptoms only self-management plans for control of asthma in general practice. BMJ 1990;301(6765):1355-9.

13. Silverman RA, Stevenson L, Hastings HM. Age-related seasonal patterns of emergency department visits for acute asthma in an urban environment. Ann Emerg M ed 2003;42:577-86

14. Weiss KB. Seasonal trends in US asthma hospitalizations and mortality. JAMA 1990;263:2323-8.

15. Riccioni G, Di Stefano F, De Benedictis M, et al. Seasonal variability of nonspecific bronchial responsiveness in asthmatic patients with allergy to house dust mites. Allergy Asthma Proc 2001;22:5-9.

16. Dharmage S, Bailey M, Raven J, et al. Mouldy houses influence symptoms of asthma among atopic individuals. Clin Exp Allergy 2002;32:714-20.

17. Partridge MR. Written asthma action plans. Thorax 2004;59(2):87-8.

18. Gibson P. Written action plans for asthma: an evidence-based review of the key components. Thorax 2004;59:94-9.

19. Hylkema MN, Sterk PJ, de Boer WI, Postma DS. Tobacco use in relation to COPD and asthma. Eur Respir J 2007;29(3):438-45.

20. Wark PA, Gibson PG. Asthma exacerbations 3: Pathogenesis. Thorax 2006; 61(10):909-15.

21. Schwartz J, Timonen KL, Pekkanen J. Respiratory effects of environmental tobacco smoke in a panel study of asthmatic and symptomatic children. Am J Respir Crit Care Med 2000;161(3 Pt 1):802-06.

22. Just J, Segala C, Sahraoui F, Priol G, Grimfeld A, Neukirch F. Short-term health effects of particulate and photochemical air pollution in asthmatic children. Eur Respir J 2002;20:899-906.

23. Rabinovitch N, Strand M, Gelfand EW. Particulate levels are associated with early asthma worsening in children with persistent disease. Am J Respir Crit Care Med 2006:173:1054-5.

24. Pazza V, Serrano Y, Picado C, Sanchis J; High Risk Asthma Research Group. 1 Frequency and clinical characteristics of rapid-onset fatal and near-fatal asthma. Eur Respir J 2002;19:846-52.

25. Kơrhonen K, Reijonen TM, Remes K, Malmstrom K, Klaukka T, Korppi M. Reasons for and costs of hospitalization for pediatric asthma: a prospective 1year follow-up in a population-based setting. Pediatr Allergy Immunol 2001;12:331-8.

26. Sturdy PM, Victor CR, Anderson HR, et al. Psychological, social and health behaviour risk factors for deaths certified as asthma: a national case-control study. Thorax 2002;57:1034-9.

27. Bousquet J, Van Cauwenberge P, Khaltaev N; Aria Workshop Group; World Health Organization. Allergic rhinitis and its impact on asthma. J Allergy Clin Immunol 2001;108(Suppl):S147-334.

28. Antonicelli L, Micucci $C$, Voltolini $S$, et al. Allergic rhinitis and asthma comorbidity: ARIA classification of rhinitis does not correlate with the prevalence of asthma. Clin Exp Allergy 2007;37(6):954-60.

29. Calhoun WJ. Nocturnal asthma. Chest 2003;123(Suppl):399S-405S.

30. Gibson PG, Henry RL, Coughlan JL. Gastro-oesophageal reflux treatment for asthma in adults and children. Cochrane Database Syst Rev 2003 (2) doi:10.1002/14651858.CD001496.

31. Chinese GERD Study Group. Value of reflux diagnostic questionnaire in the diagnosis of gastroesophageal reflux disease. Chin J Dig Dis 2004;5:51-5.

32. Shore SA, Fredberg JJ. Obesity, smooth muscle, and airway hyperresponsiveness. J Allergy Clin Immunol 2005;115:925-7.

33. Hakala K, Stenius-Aarniala B, Sovijärvi A. Effects of weight loss on peak flow variability, airways obstruction, and lung volumes in obese patients with asthma. Chest 2000;118:1315-21.

34. Tan KS. Premenstrual asthma: epidemiology, pathogenesis and treatment. Drugs 2001;61(14):2079-86.

35. Vrieze A, Postma DS, Kerstjens HA. Perimenstrual asthma: a syndrome without known cause or cure. J Allergy Clin Immunol 2003;112(2):271-82.

36. Hanley SP. Asthma variation with menstruation. Br J Dis Chest 1981;75:306-08. 37. Yawn BP. Asthma in women: the hormonal link. Female Patient 2003;28:34-41. 
38. Svanes C, Real FG, Gislason T, Jansson C, Jogi R, Norrman E, Nystrom L, Toren K, Omenaas E. Association of asthma and hay fever with irregular menstruation. Thorax 2005;60(6):445-50.

39. Adams RJ, Wilson DH, Taylor AW, et al. Coexistent chronic conditions and asthma quality of life: a population-based study. Chest 2006;129:285-91.

40. Blackburn D, Hux J, Mamdani M. Quantification of the risk of corticosteroidinduced diabetes mellitus among the elderly. J Gen Intern Med 2002;17:71720.

41. Anderson SD. Single-dose agents in the prevention of exercise-induced asthma: a descriptive review. Respir Med 2004;3:365-79.

42. Jenkins C, Costello J, Hodge L. Systematic review of prevalence of aspirin induced asthma and its implications for clinical practice. BMJ 2004;328:434-40.

43. Covar RA, Macomber BA, Szefler SJ. M edications as asthma triggers. Immunol Allergy Clin North Am 2005;25:169-90.

44. Schmaling KB, McKnight PE, Afari N. A prospective study of the relationship of mood and stress to pulmonary function among patients with asthma. J Asthma 2002;39:501-10.

45. Bateman ED, Boushey HA, Bousquet J, et al. Can guideline-defined asthma control be achieved? The Gaining Optimal Asthma control study. Am J Respir Crit Care Med 2004;170:836-44.

46. Yawn B. Participatory research in rural primary care. Minn Med 2004;87:52-4.

47. Williams LK, Pladevall $M, X i H$, et al. Relationship between adherence to inhaled corticosteroids and poor outcomes among adults with asthma. J Allergy Clin Immunol 2004;114:1288-93.

48. Bhogal S, Zemek R, Ducharme FM . Written action plans for asthma in children. Art. No.: CD005306. DOI: 10,1002/14651858.CD005306.pub2.

49. Yawn B. Comparison of once-daily intranasal corticosteroids for the treatment of allergic rhinitis: are they all the same? MedGenMed 2006;8(1):23.

50. Corren J, Manning BE, Thompson SF, Hennessy S, Strom BL. Rhinitis therapy and the prevention of hospital care for asthma: a case-control study. J Allergy Clin Immunol 2004;113:415-19.

51. Aaron SD, Fergusson D, Dent R, Chen $Y$, Vandemheen $K L$, Dales RE. Effect of weight reduction on respiratory function and airway reactivity in obese women. Chest 2004;125:2046-52.

52. Gluck JC, Gluck PA. Asthma controller therapy during pregnancy. Am J Obstet Gynecol 2005;192:36-80.

53. National Heart, Lung, and Blood Institúte; National Asthma Education and Prevention Program Asthma and Pregnancy Working Group. NAEPP expert panel report. Managing asthma during pregnancy: recommendations for pharmacologic treatment - 2004 update. J Allergy Clin Immunol 2005;115:34-46.

54. Murphy VE, Gibson PI, Talbot CG, Kessell G, Clifton VL. Asthma selfmanagement skills and the use of asthma education during pregnancy. Eur Respir J 2005;26(3):435-41.

55. Chambers CV, Markson L, Diamond JJ, Lasch L, Berger M. Health beliefs and compliance with inhaled corticosteroids by asthmatic patients in primary care practices. Respir Med 1999;93:88-94.

56. Clark NM, Gong M, Schork MA, et al. Long-term effects of asthma education for physicians on patient satisfaction and use of health services. Eur Respir J 2000;16:15-21.

57. Onyirimba F, Apter A, Reisine $S$, et al. Direct clinician-to-patient feedback discussion of inhaled steroid use: its effect on adherence. Ann Allergy Asthma Immunol 2003;90:411-15.

58. Gibson PG, Powell H, Coughlan J, et al. Self-management education and regular practitioner review for adults with asthma. Cochrane Database Syst Rev 2002 (3) doi:10.1002/14651858.CD001117.

59. Ring N, Malcolm C, Wyke S, et al. Promoting the use of Personal Asthma Action Plans: a systematic review. Prim Care Resp J 2007;16(5):271-83. doi:10.3132/pcrj.2007.00049

60. Yawn BP, Brenneman SK, Allen-Ramey FC, Cabana MD, Markson LE. Assessment of Asthma Severity and Asthma Control in Children. Pediatrics 2006;118(1):322-9.

61. Vollmer WM. Assessment of asthma control and severity. Ann Allergy Asthma Immunol 2004;93:409-13.

62. Nathan RA, Sorkness CA, Kosinski M, et al. Development of the asthma control test: a survey for assessing asthma control. J Allergy Clin Immunol 2004;113:59-65.

63. QualityM etrics, Inc. ChildhoodAsthma Control Test for children with asthma 4 to 11 years old. http://www. asthmacontrol.com/AsthmaControlTestChild.html. 2005. GlaxoSmithkline, Inc.

64. Lenoir M. Williamson A, Stanford RH, Stempel DA Assessment of asthma control in a general. population of asthmatics. Curr Med Res Opin 2006; 22(1):17-22:

65. Vollmer WM, Markson LE, O'Connor E, et al. Association of asthma control with health care utilization and quality of life. Am J Respir Crit Care Med 1999;160:1647-52.

O66. Vollmer WM, Markson LE, O'Connor E, Frazier EA, Berger M, Buist AS. Association of asthma control with health care utilization: a prospective evaluation. Am J Respir Crit Care Med 2002;165:195-9.

67. Skinner EA, Diette GB, Algatt-Bergstrom PJ, et al. The Asthma Therapy Assessment Questionnaire (ATAQ) for children and adolescents. Dis Manag 2004;7:305-13.

68. Narayanan S, Edelman JM, Berger M L, M arkson LE. Asthma control and patient satisfaction among early pediatric users of montelukast. J Asthma 2002;39:757-65.

69. Juniper EF, O'Byrne PM, Guyatt GH, Ferrie PJ, King DR. Development and validation of a questionnaire to measure asthma control. Eur Respir J 1999;14:902-07. 
Appendix A. Reflux disease questionnaire for diagnosis of gastro-oesophageal reflux disease ${ }^{22}$

For each statement, the respondent is asked to grade each of the following symptoms based on a scale of:

\begin{tabular}{|l|l|l|l|l|l|}
\hline $\mathbf{0}$ & Did not have & $\mathbf{1}$ & Less than 1 day a week & $\mathbf{2}$ & 1 day a week \\
\hline $\mathbf{3}$ & 2 to 3 days a week & $\mathbf{4}$ & 4 to 6 days a week & $\mathbf{5}$ & Daily \\
\hline
\end{tabular}

Thinking about your symptoms over the last 4 weeks, how often did you have the following:

a) A burning feeling behind your breastbone

b) Pain behind your breastbone

c) A burning feeling in the centre of the upper stomach

d) A pain in the centre of the upper stomach

e) An acid taste in your mouth

f) Unpleasant movement of material upwards from the stomach

For each statement, the respondent is asked to grade each of the following symptoms based on a scale of:

\begin{tabular}{|l|l|l|l|l|l|}
\hline $\mathbf{0}$ & Did not have & $\mathbf{1}$ & Very mild & $\mathbf{2}$ & M ild \\
\hline $\mathbf{3}$ & Moderate & $\mathbf{4}$ & M oderately severe & $\mathbf{5}$ & Severe \\
\hline
\end{tabular}

Thinking about symptoms over the last 4 weeks, how would you rate the following?

a) A burning feeling behind your breastbone

b) Pain behind your breastbone

c) A burning feeling in the centre of the upper stomach

d) A pain in the centre of the upperstomach

e) An acid taste in your mouth

f) Unpleasant movement of material upwards from the stomach 